\title{
Recent Developments in the Pathogenesis and the Pathological Classification of IgA Nephropathy
}

\author{
Muhammed Mubarak and Javed I. Kazi \\ Histopathology Department, Sindh Institute of Urology and Transplantation, Karachi \\ Pakistan
}

\section{Introduction}

IgA nephropathy (IgAN), also known as Berger's disease, is the most common primary glomerular disease world wide and a significant cause of end-stage renal disease (ESRD) in many parts of the world (Floege \& Feehally, 2000; Geddes et al., 2003; Julian et al., 1988). It was first described in 1968 in Paris, France (Berger \& Hingalis, 1968), but now the disease is known to have a cosmopolitan distribution (Ballardie et al., 1987; Chandrika, 2009; D' Amico, 1985; Koyama et al., 1997; Lai et al., 1999; Mubarak, 2009; Power et al., 185; Rivera et al., 2004; Schena, 1997; Seedat et al., 1988; Sinniah, 1980; Strata P, et al., 1995; Yahya et al., 1997). Significant advancements have been made during last four decades in understanding the etiology, pathogenesis, classification, and treatment of this enigmatic disease. In this chapter, we discuss briefly about the historical background, epidemiology, etiology, pathogenesis, pathology, treatment, and recent developments in the diagnosis and prognosis of IgAN with particular emphasis on a recent clinicopathological classification developed through international collaboration by the members of International IgAN network in conjunction with renal pathology society (RPS). This classification is simple, easy to apply, fairly reproducible, and clinically pre-validated, and provides a role model for classifying other renal diseases in similar manner.

\section{Historical background}

IgAN was first described by Berger and Hingalis in France in 1968 as a renal glomerular disease characterized by the predominant or co-dominant IgA containing immune complex deposits in the mesangium of the glomeruli (Berger \& Hingalis, 1968). Thus, its diagnosis required, and still so, the histopathologic and immunoflourescence (IF) evaluation of the invasive procedure of renal biopsy. No blood or urinary test has been developed yet to replace the renal biopsy for its accurate diagnosis. Traditionally, the disease was considered to be a benign disease, due mainly to its very slow rate of progression, as is apparent from its earlier synonym of "benign familial hematuria" and to be confined to France. However, soon it was realized, as evidence accumulated from subsequent long term follow-up studies from different parts of the world, that both the above assumptions about IgAN were wrong, as will be discussed below in the epidemiology and the prognosis of the disease. 


\section{Epidemiology and magnitude of the problem}

The epidemiology of $\operatorname{IgAN}$ is both interesting and intriguing in that, although cosmopolitan in distribution, there is a significant variability in the reported incidence and prevalence of the disease in different countries. Very few population based incidence studies on IgAN have been reported in the literature. The reported incidence in different parts of Western Europe has varied from 15 to 40 new cases per million population per year (Rivera et al., 2004; Schena, 1997; Strata P, et al., 1995). Majority of the studies have calculated the frequency of IgAN as a percent of all native renal biopsies performed for a variety of clinical indications. The highest prevalence (upto 60\%) has been reported in native renal biopsy series from Japan, Korea, China, Singapore, Western Europe, and Australia (Ballardie et al., 1987; D’ Amico, 1985; Kazi et al., 2009; Koyama et al., 1997; Lai et al., 1999; Power et al., 185; Rivera et al., 2004; Schena, 1997; 1988; Sinniah, 1980; Strata P, et al., 1995). In contrast, studies from United States have reported very low rates at 2 to 10 percent, with the exception of a 38 percent incidence in the Navajo Indians in New Mexico (Julian et al., 1988). Nearly similar rates have been reported from Africa, Middle East, and some parts of Asia, including India, and Pakistan (Chandrika, 2009; D'Amico, 1985; Mubarak, 2009; Narasimhan et al., 2006; Seedat et al., 1988; Yahya et al., 1997). The exact cause for this marked variability in the epidemiology of the disease is not known, but it most probably is related to the differences in biopsy indications and the extent of pathologic evaluation of the renal biopsies.

\section{Etiology}

The vast majority of cases of IgAN are primary or idiopathic, and as their name suggests, their etiology is still not known (Barratt et al., 2004; Donadio \& Grande, 2002; Floege \& Feehally, 2000; Galla, 1995). The disease is, in most cases, a sporadic disorder. However, cases of familial and secondary IgAN are well documented and these have proved very useful for the insight they have provided for a better understanding of the pathogenetic mechanisms underlying the disease (Barratt et al., 2004; Donadio \& Grande, 2002; Galla, 1995). A list of these secondary causes is shown in table 1.

Diseases of the liver: alcoholic, primary biliary, or cryptogenic cirrhosis; hepatitis B; chronic schistosomiasis

Diseases of the gastrointestinal tract: celiac disease; chronic ulcerative colitis; Crohn's disease

Dermatologic diseases: dermatitis herpetiformis; psoriasis

Pulmonary diseases: sarcoidosis, idiopathic pulmonary hemosiderosis; cystic fibrosis; bronchiolitis obliterans

Malignant neoplasms: carcinoma of the lung, larynx, and pancreas; mycosis fungoides Infective agents: human immunodeficiency virus; leprosy

Immunologic disorders: systemic lupus erythematosus; rheumatoid arthritis; cryoimmunoglobulinemia; psoriatic arthritis; ankylosing spondylitis; Sjögren's syndrome; Behçet's syndrome; Reiter's syndrome; familial immune thrombocytopenia; Goodpasture's syndrome

Table 1. List of diseases/conditions associated with IgA deposits in the kidney. 


\section{The pathogenetic mechanisms}

The mechanism of development of IgAN is still largely unresolved. However, many advances have been made, especially during the last decade in unraveling some of the steps involved in the pathogenetic pathway of the disease. This has been made possible by the numerous experimental studies conducted on animal models and clinical studies in humans on the sporadic as well as rare genetic forms of the disease (Barratt et al., 2004; Donadio \& Grande, 2002; Floege \& Feehally, 2000; Galla, 1995). The postulated mechanisms of pathogenesis are shown in Fig. 1.

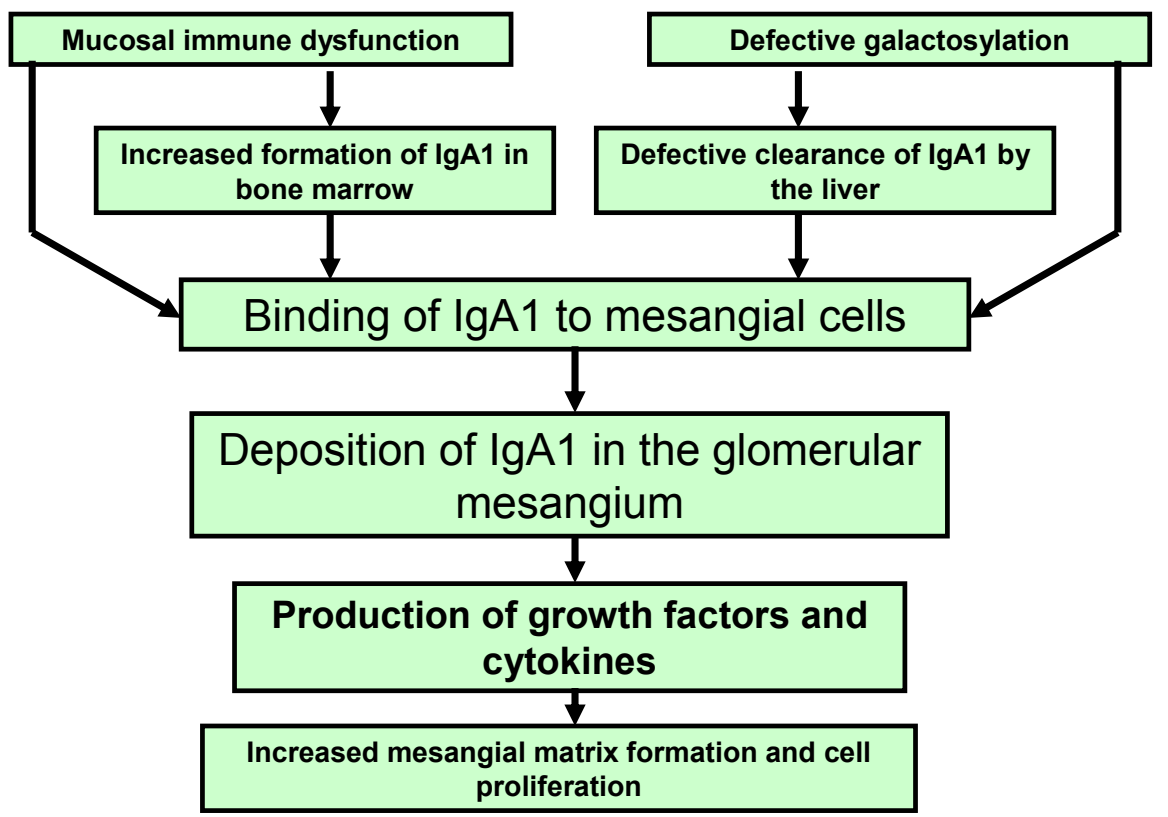

Fig. 1. Schematic diagram showing the main steps involved in the pathogenesis of IgA nephropathy. The final common step consists of deposition of polymers of IgA1 molecules or their complexes in the mesangium. These, then induce injury and stimulate mesangial cells and recruited inflammatory cells to release mediators which result in the morphological expression of glomerular abnormaliteis.

As is apparent from this figure, the final common pathway in the process consists of an accumulation of an abnormally galactosylated polymers of IgA1 (pIgA1) molecules and/or complexes in the mesangial regions of the glomeruli. It is plausible that numerous pathogenetic pathways are involved and converge on this central and unifying stage in the pathway (Barratt et al., 2004). The likely events of pathogenesis implicated in different studies run the whole span of IgA immune system abnormalities from increased production of aberrantly galactosylated pIgA1 molecules by a putative abnormal subclone of B lymphocytes, to decreased clearance by the liver, to host immune response to abnormal pIgA1 molecules, to physicochemical mechanisms leading to abnormal accumulation of pIgA1 in the mesangium (Coppo \& Amore, 2004). These bind to and interact with 
mesangial cells leading to their activation and proliferation. Activated mesangial cells as well as infiltrating inflammatory cells, not only proliferate but also produce proinflammatory cytokines, chemokines, and growth factors, which initiate tissue injury. A number of cytokines have been studied in detail including platelet derived growth factor (PDGF) $\beta$ - chain and transforming growth factor- $\beta$ (TGF- $\beta$ ) for their roles in the ultimate expression of the disease (Barratt et al., 2004; Donadio \& Grande, 2002; Floege \& Feehally, 2000; Galla, 1995). There is also evidence of local complement activation induced by alternative pathway triggered by pIgA1 molecules in the mesangium. There are species differences in the molecular structure of $\operatorname{IgA}$ and unique features of human $\operatorname{IgA} 1$ have prevented development of satisfactory animal models for the early stages of IgAN. A fully humanized mouse model of disease is still awaited to better extrapolate the steps of the pathogenesis to clinical disease in humans. It is probable that events downstream of pIgA1 deposition, which result in glomerular inflammation and scarring, are not specific to IgAN but generic to many immune complex mediated forms of glomerulonephritis (Barrat et al., 2004). There is also preliminary evidence in favor of genetic factors in the predisposition, development, and progression of the disease (Hsu et al., 2000). However, there is no single "IgA gene" involved, and it is likely that multiple interacting genes will eventually be discovered that predispose to the disease. More recently, IgAN has also been categorized as a form of auto-immune disease, in which autoantibodies of the IgG class are formed against aberrantly galactosylated IgA1 molecules. A complete understanding of the pathogenesis along with etiology is necessary if we are to develop a specific and targeted therapy for the disease. Future molecular biologic studies will certainly help in this discovery of missing steps in the pathogenesis (Barratt et al., 2004; Donadio \& Grande, 2002; Floege \& Feehally, 2000; Galla, 1995; Novak et al., 2001).

\section{Pathology}

The diagnosis of IgAN on renal biopsy requires a detailed pathological evaluation of the biopsy by light microscopy (LM), IF, and electron microscopy (EM). In particular, IgAN is a diagnosis of IF microscopy. The features of IgAN on each of these investigations are described below:

\subsection{Light microscopy}

IgAN is primarily an immune-complex mediated GN, and like lupus nephritis manifests a wide range of morphological appearances on LM. Thus, on LM, IgAN is quite heterogenous. The range of morphologic alterations seen on renal biopsy under the LM spans the whole spectrum from minor changes in the glomeruli and the surrounding parenchyma to full blown crescentic GN (CresGN), except for pure membranous pattern. The list of morphological patterns seen in IgAN is shown in table 2 and in figures 2 to 6 . All the above patterns of glomerular injury in IgAN are unified by the presence of predominant or codominant IgA deposits in the glomerular mesangium on IF microscopy (Galla, 1995). The reason for this varying phenotypic expression of the disease in different patients is not completely known, but may be related to both the abnormalities of IgA molecule and the host factors. This phenotypic variability of IgAN on LM is expressed as clinical heterogeneity of the disease, but the clinical histologic correlation is not perfect. This variability in morphology of the disease has led to efforts to classify the disease into prognostic groups. 


\author{
Light microscopy \\ Glomeruli \\ Minor changes \\ Varying degrees of mesangial proliferation \\ Mesangiocapillary pattern \\ Focal segmental glomerular sclerosis \\ Crescentic GN \\ Diffuse proliferative and exudative GN \\ Chronic sclerosing GN
}

\title{
Tubulo-interstitial component
}

Varying degrees of tubular atrophy and interstitial scarring, usually commensurate with glomerular changes

\section{Vascular changes}

Usually mild fibro-intimal thickening of arteries, commensurate with the degree and duration of hypertension

Thrombotic microangiopathy

\section{Immunoflourescence}

IgA-dominant or co-dominant, is sine qua non for the diagnosis of IgA nephropathy Other immunoglobulins and complement components- variably present

Lambda chain predominant

\section{Electron microscopy}

Variable degree of mesangial proliferation and glomerular inflammation Large electron dense deposits in the mesangium, paramesangium and occasionally, in other locations

Table 2. Pathologic features of IgA nephropathy on light microscopy, immunoflourescence and electron microscopy.

Many pathological classifications have been proposed over time, but none has achieved international acceptance (Hass, 1997; Manno et al., 2007). More recently, a new pathological classification of IgAN, termed "The Oxford classification of IgAN" has been formulated and published (Cattran et al., 2009; Roberts et al., 2009). It is unique and unprecedented type of classification that was validated before it was formulated and published, in contrast to the traditional approach to disease classifications.

It is very simple and based on only four pathological features on renal biopsy and is easy to apply in routine practice. This classification is pre-validated, evidence based, and of good interobserver reproducibility and most important of all, proves independent prognostic value of pathological features on renal biopsy. Although, pre-validated, the scheme does require more validation studies in routine practice in prospective cohorts and in different study populations. The reasons are; although the sample size in the original study cohort was large, it was limited in scope, the retrospective design of the study, the use of only LM assessment for the classification, and most important of all, the unaddressed issue of treatment strategies. LM features are of independent prognostic value in IgAN and have been investigated by many researchers for classification purpose. 


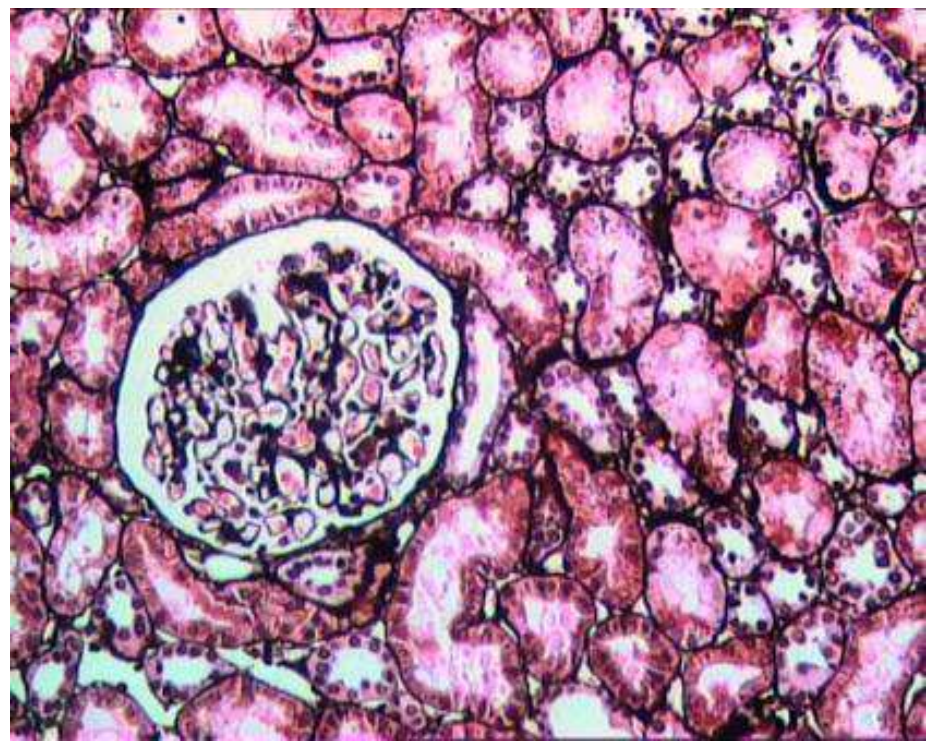

Fig. 2. Medium-power view showing a glomerulus with minor changes on light microscopy. Although rare, this pattern can be seen in IgA nephropathy. The surrounding tubules and interstitium show no significant pathology. (Jones' methenamine silver, $\times 200$ ).

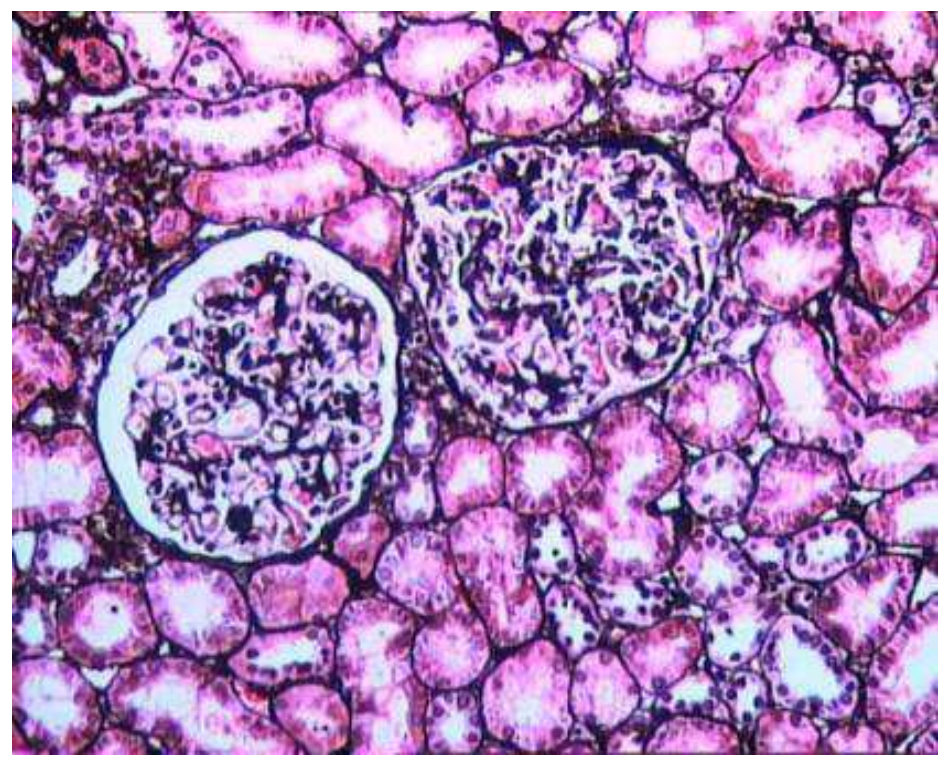

Fig. 3. Medium-power view showing two glomeruli showing mild prominence of the mesangium, but there is no significant increase in the mesangial cellularity in another case of IgA nephropathy. Surrounding parenchyma is unremarkable. (Jones' methenamine silver, $\times 200)$. 


\subsection{Immunoflourescence microscopy}

The sine qua non for the diagnosis of IgAN is the presence of dominant or co-dominant deposits of IgA in the mesangial area of the glomeruli on IF microscopy. The intensity of staining can vary from $1+$ to $3+$ on a semiquantitative scale of 0 to $3+$ (Fig. 7 ). A trace positivity of $\operatorname{IgA}$ is not sufficient for the definitive diagnosis of $\operatorname{IgAN}$. The distribution of IgA is predominantly mesangial, with extension of the deposits into peripheral capillary walls in approximately one third of cases. The deposited IgA consists mainly of IgA1 rather than $\operatorname{IgA} 2$, and is accompanied by other immunoglobulins and complement components in many cases. IgG and IgM are frequently present, but their intensity is generally lower than that of IgA. In contrast, C3 deposits are almost universal and bright in intensity, whereas $\mathrm{Clq}$ is found only rarely and usually is of low intensity. The presence of dominant $\mathrm{C} 1 \mathrm{q}$ with bright IgA should raise a differential diagnosis of lupus nephritis. Light chain typing of IgAN on IF shows a predominance of lambda light chains over kappa chains, a distinctive feature of IgAN. Fibrin may be found in severe forms of IgAN with crescent formation. Some IF features, such as peripheral capillary location of IgA and mesangial IgG, are supposedly of prognostic importance in IgAN (Bellur et al., 2011).

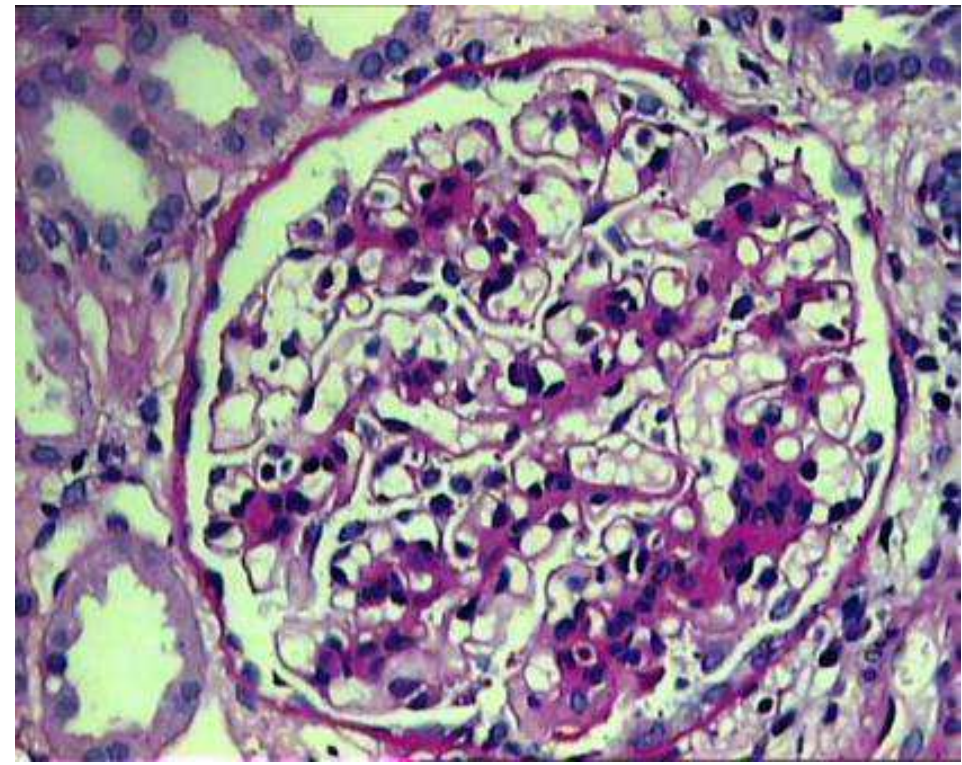

Fig. 4. High-power view showing a glomerulus with segmental and moderate degree mesangial hypercellularity. The patchy involvement of the glomeruli is characteristic of IgA nephropathy. Peripheral capillary walls are thin and capillary lumena patent. The later features distinguishes this pattern from mesangiocapillary pattern. This is the typical and the most common morphological pattern seen in IgA nephropathy. (PAS, $\times 400$ ). 


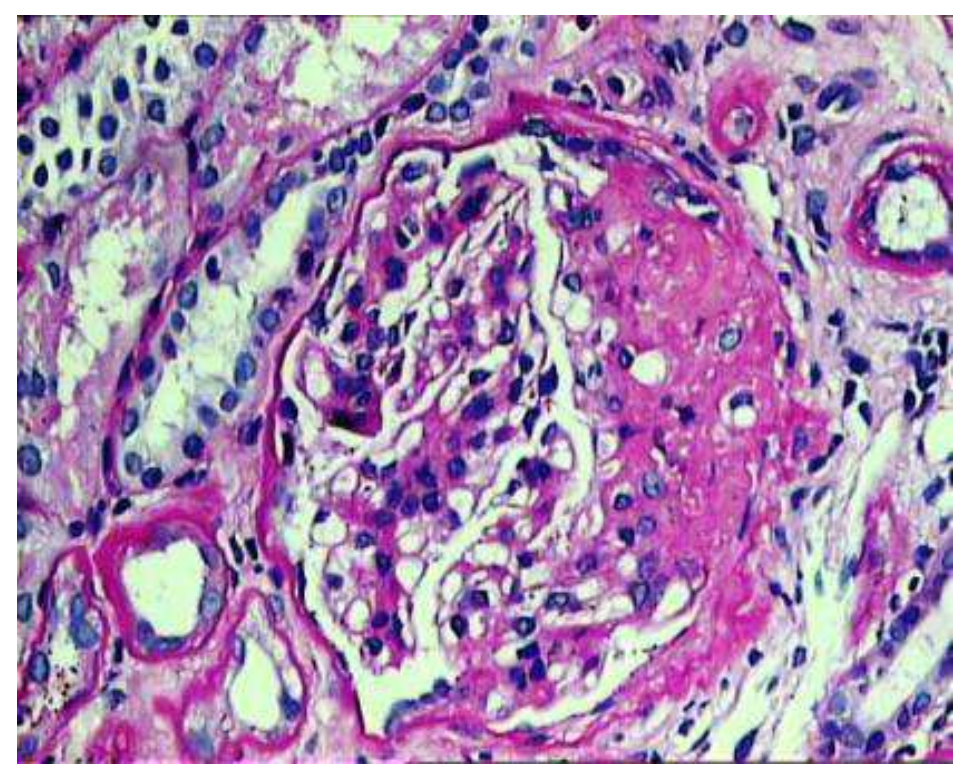

Fig. 5. High-power view showing a segmental scar with adhesion formation with Bowman's capsule. The unscarred portion of the glomerulus shows mild mesangial hypercellularity.

This morphologic pattern is common in IgA nephropathy and is distinguished from idiopathic focal segmental glomerulosclerosis by the presence of IgA deposits on immunoflourescence and electron microscopy. (PAS, ×400).

\subsection{Electron microscopy}

Ultra-structurally, the main finding apart from the secondary changes of mesangial proliferation and other alterations, is the deposition of large, frequently triangular shaped, electron-dense deposits, most often, in the mesangium and para-mesangial area of the glomeruli (Fig. 8, 9). The deposits may on rare occasions be found in other locations within the glomeruli. The amount of deposits varies from case to case, and in some cases, massive deposits are found throughout the mesangium, extending into the sub-endothelial location. Peripheral capillary wall deposits in subepithelial, subendothelial, and intramembranous locations are found in approximately one fourth to one third of cases of IgAN. The deposits in these loci are more common in histologically severe forms of the disease, such as cresGN and rare in the mild forms of the disease. Electron-dense deposits may not occasionally be found in typical cases of IgAN diagnosed on IF microscopy. This does not rule out the diagnosis of IgAN, as the disease is a diagnosis of IF microscopy. Moreover, the deposits may be patchy and not included in the scanty material usually examined under the EM.

In addition to the electron-dense deposits, the glomeruli show expansion of the mesangium and mesangial cell proliferation. These alterations parallel those seen on LM. There is also focal to diffuse loss of foot processes of podocytes, especially in those cases presenting with nephrotic range proteinuria. Focal areas of irregular thinning of GBM are seen in many cases of IgAN; these are not synonymous with concurrent IgAN and thin basement membrane disease (TBMD), and may contribute to the hematuria. Occasionally, IgAN co-exists with other glomerulopathies, such as TBMD, minimal change disease (MCD), membranous GN 
$(\mathrm{MN})$, etc. In those cases, features of both diseases will be found on ultrastructural study. No prognostic importance is attached with the ultrastructural alterations in IgAN.

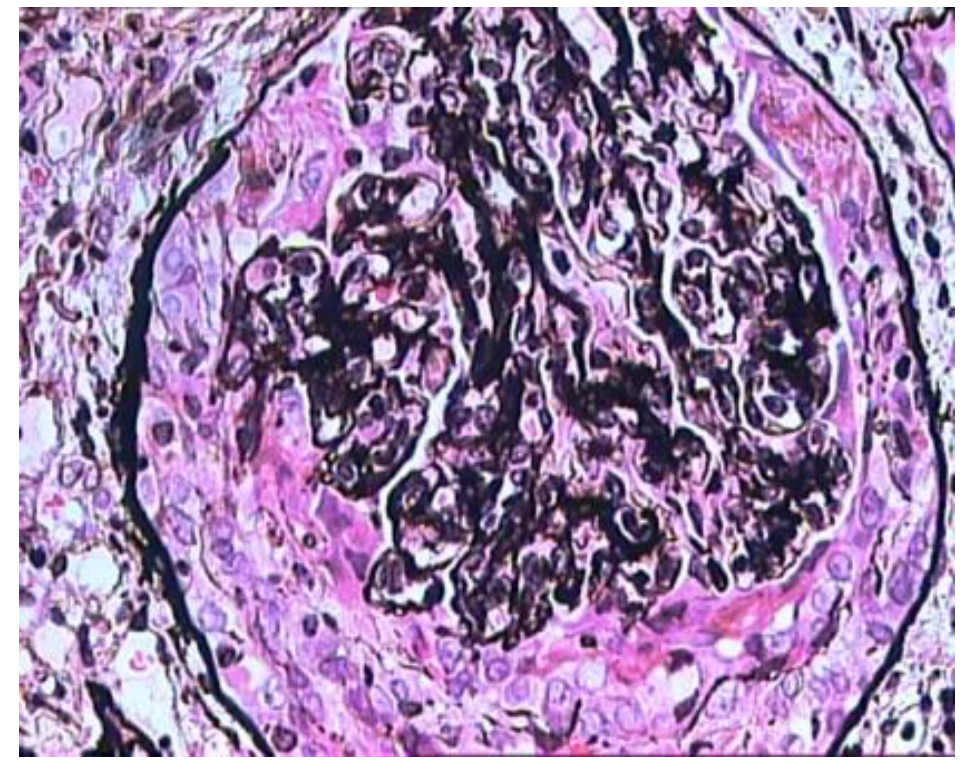

Fig. 6. High-power view showing a glomerulus with marked extracapillary cellular proliferation forming a crescent. The glomerular tufts are collapsed. This morphological pattern is rare in IgA nephropathy, but is well described, and leads rapidly to renal failure. (Jones' methenamine silver, $\times 400$ ).

\section{Clinical presentation}

Similar to its pathology and clinical course, IgAN is also heterogeneous in clinical presentation. It presents in a variety of ways. It can occur at any age, but majority of cases are seen in adolescents and young adults. The disease is more common in males than females, the male to female varying from less than 2:1 in Japan and other oriental studies to more than 6:1 in the studies from northern Europe and United States. The classic presentation is with painless usually episodic gross or persistent microscopic hematuria, usually developing concurrently with upper respiratory tract infection (hence the use of synonym of synpharyngitic GN), gastroenteritis, or pneumonia. The presenting illness of episodic, grossly visible hematuria is more common in younger patients, whereas that of microscopic hematuria and proteinuria is more frequent in older individuals. Proteinuria is usually mild and usually associated with persistent microscopic hematuria. Occasional cases present with nephrotic range proteinuria. IgAN may rarely present with acute or chronic renal failure. Hypertension is rarely diagnosed at the time of presentation, but its frequency increases as the disease duration is increased or when patients develop ESRD (Barratt et al., 2004; Donadio \& Grande, 2002; Floege \& Feehally, 2000; Galla, 1995). 


\section{Differential diagnosis}

A wide range of diseases are associated with the deposition of IgA in the glomeruli, and these come into the differential diagnosis of IgAN. The most common being HenochSchonlein purpura (HSP), believed to be a systemic form of the same disease process as IgAN, with similar histopathological and IF findings in the glomeruli. The presence of systemic symptoms, such as purpuric rash, arthralgias, and abdominal pain help in this differential diagnosis. Post-infectious GN (PIGN) may also present with microscopic hematuria and comes in the clinical differential of IgAN, but the onset of hematuria occurs 7 to 14 days after, and not at the time of infection as in IgAN. A large number of other diseases are characterized by renal pathology resembling IgAN. These are listed in table 1 and are distinguished from primary IgAN by their associated signs and symptoms.

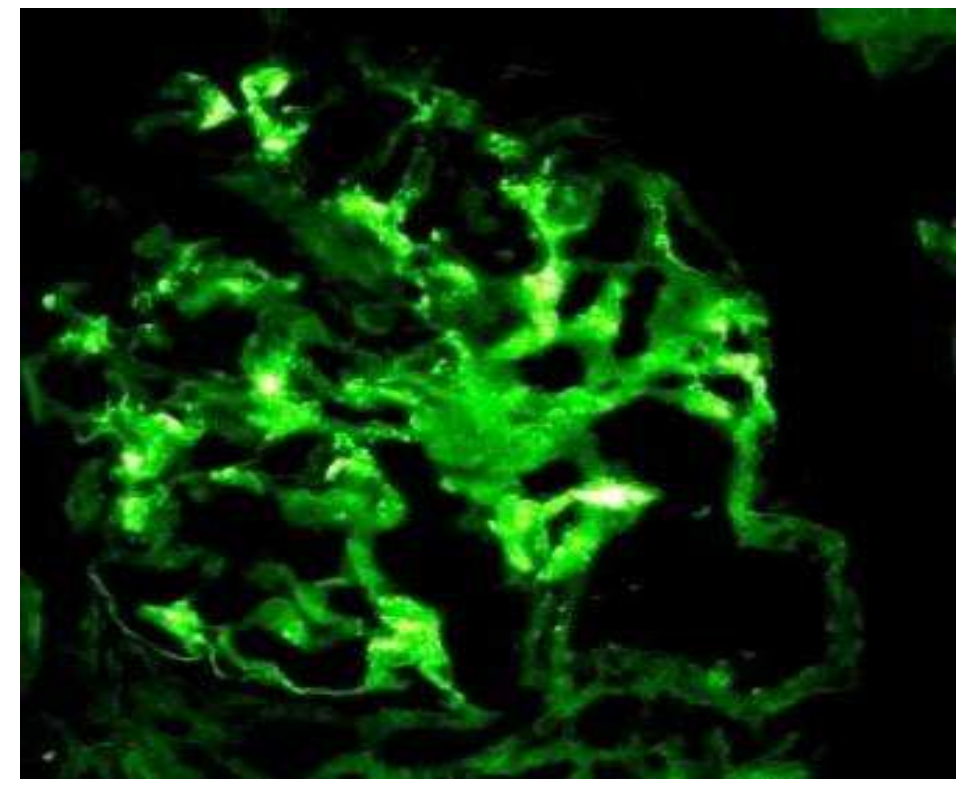

Fig. 7. High-power view showing a glomerulus with diffuse, granular, strong $(3+$ on a scale of 0 to $3+$ ) deposits of IgA in the mesangial regions. Focally, the deposits are extending into the peripheral capillary walls. (FITC-conjugated $\operatorname{IgA}, \times 400$ ).

\section{Risk of progression and classification systems}

Just like its morphology, the disease is also heterogeneous in its clinical evolution. Although the disease was traditionally considered as benign process, it is now known to lead to a slowly progressive decline in renal function with ESRD developing in upto $30-40 \%$ of patients 20 years after initial presentation (Barratt et al., 2004; Donadio \& Grande, 2002; Galla, 1995; Geddes et al., 2003). 


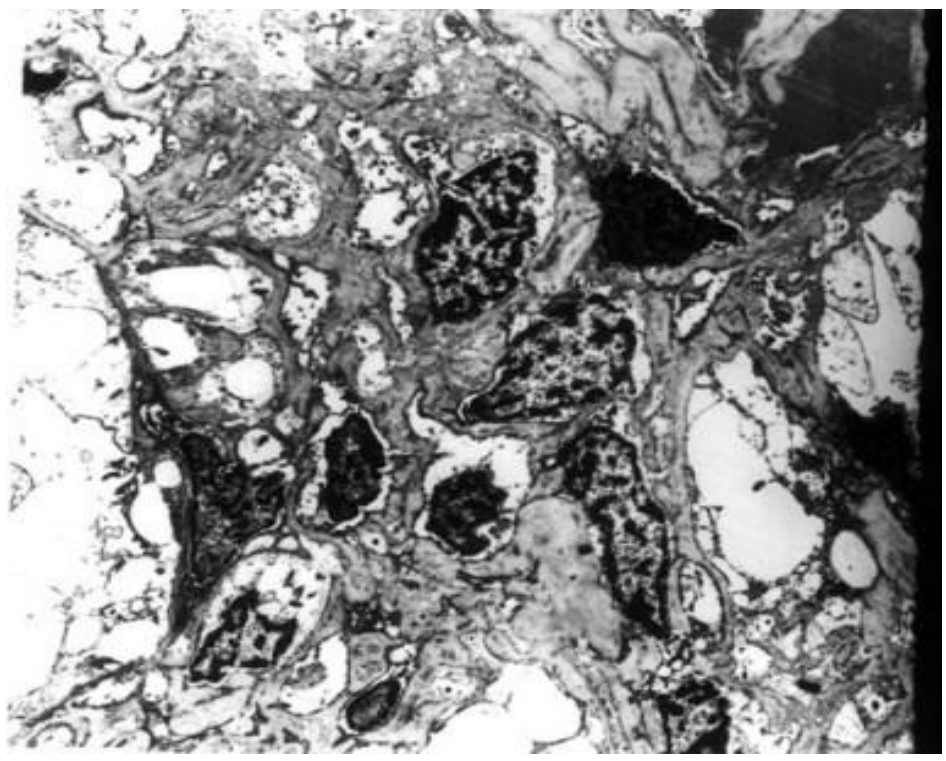

Fig. 8. Low-power electron photomicrograph showing mild mesangial proliferation associated with many large, triangular shaped, electron dense deposits in the mesangium. (Lead citrate \& Uranyl acetate, $\times 5000$ ).

The clinical course in other patients is non-progressive, while in a minority of individuals it leads to a rapidly progressive course to ESRD. Most of the research is focused on identifying the predictive factors for the subset of patients with slowly progressive forms of the disease. Long term follow up studies show variable rates of disease progression in different parts of the world (Geddes et al., 2003). Many attempts have been made in recent past in identifying clinical, familial, laboratory, immunological, genetic, and morphologic features on renal biopsies which can predict the outcome in individual patients. However, many of these parameters have been investigated by simple univariate analysis, and the independent prognostic value of these factors has not been established. Among these, the predictive value of serial estimations of clinical and laboratory parameters is proved beyond any doubt. But whether, pathological features on renal biopsy are of any significant and independent predictive value has remained controversial till very recently. This is because of the fact that almost all pathologic studies carried out by different investigators in different parts of the world have produced conflicting results. Some investigators tried to incorporate the various morphological features observed under LM into a pathologic classification of IgAN, but none succeeded in achieving international approval (Hass, 1997; Lee et al., 2005; Manno et al., 2007). More recently, an international working group of nephrologists and nephropathologists with keen interest and expertise in IgAN have promulgated a novel classification of IgAN, termed "The Oxford classification of IgAN" (Cattran et al., 2009; Roberts et al., 2009).

This scheme was developed by using a novel and unique approach to the pathological classification of $\operatorname{IgAN}$, inasmuch as no arbitrary classes or grades are constructed, as in 


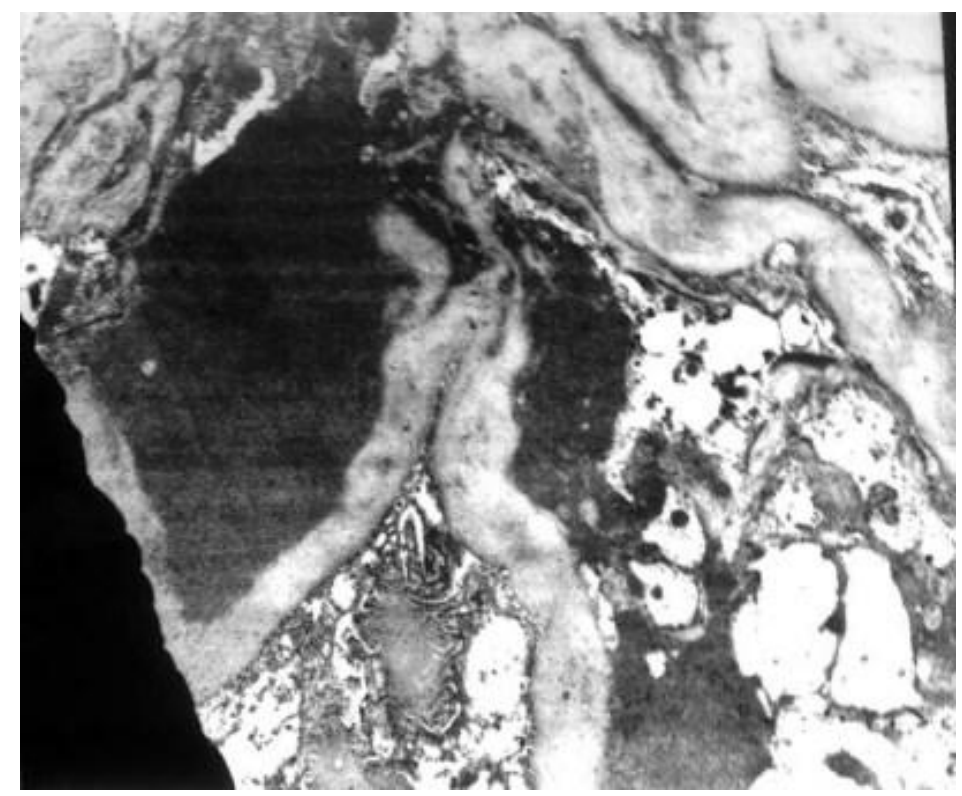

Fig. 9. High-power electron photomicrograph showing large, triangular shaped, uniformly electron dense deposits in the para-mesangial regions of the glomerulus. (Lead citrate \& Uranyl acetate, $\times 25000$ ).

previous classifications. Instead, specific pathological variables of prognostic importance independent of clinical data at the time of biopsy and follow up have been identified and scored by a rigorous iterative methodology of first defining the lesions and then testing for reproducibility and ease of scoring and finally testing them for their predictive power. This type of rigorous effort has never been employed previously in the classification of renal diseases (Cattran et al., 2009; Roberts et al., 2009). The study cohort for the final study validation project consisted of 265 adults and children with biopsy-proven IgAN from eight different countries from four continents, with a median follow-up period of 5 years. The study cohort can be considered as fairly but not completely representative of the entire clinicopathological spectrum of IgAN. It included both males and females, children and adults, nearly all racial groups, and nearly all grades of severity of the disease. However, there was a marked underrepresentation of some grades of disease, for example, very mild cases and very severe cases were very few. This classification is based on detailed analysis of retrospective clinical data obtained on these patients in concert with intense and detailed pathological review of their renal biopsy material for the identified prognostic pathological features. Thus, the classification was validated before its formulation. A set of six distinct pathology variables were identified, from around 24 original pathological features tested, on the basis of sufficient reproducibility among the nephropathologists, least propensity for sampling error, and the ease of scoring in routine practice while avoiding strong co-linearity (mesangial hypercellularity score, segmental glomerulosclerosis or adhesion, endocapillary hypercellularity, cellular or fibrocellular crescents, tubular atrophy/interstitial fibrosis, artery score). Four of them (mesangial hypercellularity score, endocapillary hypercellularity, segmental glomerulosclerosis or adhesion, and tubular atrophy/interstitial fibrosis) were 
shown in the final analysis to have independent predictive value for the final renal outcome even after taking into account all clinical and laboratory parameters available at the time of biopsy as well as during follow up. These pathological variables along with their proposed scoring (so called MEST score), which are recommended by the Oxford group, to be included in the pathology report of renal biopsy specimens from patients with IgAN, are shown in Table 3. These variables showed the independent prognostic value and a significant correlation with the clinical outcome in both univariate and multivariate analysis. The classification could not address the prognostic value of crescents due to their low prevalence in the enrolled cohort which did not include rapidly progressive cases. This classification is clinically pre-validated, evidence based with acceptable interobserver reproducibility, and most important of all, relatively simple to apply in routine practice (Cattran et al., 2009; Mubarak, 2009; Roberts et al., 2009). The case mix was fairly varied; the cases were collected from eight different centers from four main continents, to ensure international participation and consensus development. However, there are certain limitations of the classification scheme; the classification was developed by dedicated, research-oriented nephropathologists with special interest in IgAN and on a limited repertoire of cases. As discussed previously, both mild (non-progressive) and severe (rapidly-progressive) ends of IgA spectrum were not enrolled. It was retrospective by design and the impact of treatment was not explored in detail. There is definitely a scope for further refinement and validation of the scheme in other prospective cohorts of patients. It needs to be validated in routine practice among practicing pathologists throughout the world on a wide range of cases (Herzenberg et al., 2011). Moreover, the original classification is based purely on light microscopic assessment of pathological features on renal biopsies (Mubarak, 2009). No correlation with IF or EM variables was carried out during the development of this classification. More recently, the question of clinical value of immunohistologic findings in the context of the original study patients' cohort has been addressed by the core group of the researchers involved in the development of the original classification (Bellur et al., 2011). They conclude that the glomerular location of $\operatorname{IgA}$ and the presence of $\operatorname{IgG}$ correlate with mesangial and endocapillary cellularity. It is likely that the immunohistologic findings may be added to the classification in near future as more data accumulate.

\begin{tabular}{lc}
\hline Pathological features & Score \\
$\begin{array}{l}\text { 1. Mesangial hypercellularity } \\
\text { Present in } \leq 50 \% \text { of the glomeruli }\end{array}$ & \\
Present in $>50 \%$ of the glomeruli & M0 \\
2. Endocapillary hypercellularity & M1 \\
Absent & E0 \\
Present & E1 \\
$\begin{array}{l}\text { 3. Segmental glomerulosclerosis } \\
\text { Absent }\end{array}$ & $\mathrm{S} 0$ \\
Present & $\mathrm{S} 1$ \\
4. Tubular atrophy/interstitial fibrosis & \\
$\leq 25 \%$ of the cortex & $\mathrm{T} 0$ \\
$26-50 \%$ of the cortex & $\mathrm{T} 1$ \\
$>50 \%$ of the cortex & $\mathrm{T} 2$ \\
\hline
\end{tabular}

Table 3. The four key pathological features that are recommended by the Oxford group to be included in the standardized pathology reports for patients with IgA nephropathy. 
There is also need to investigate the effect of additional features which had enrollment bias in the original study ( rapidly progressive and non-progressive cases) and to investigate the combined prognostic value of adding clinical data to biological scores (e.g. proteinuria at the time of renal biopsy or during follow-up), and the last, but not the least, to detect for each lesion, the most effective treatment and the point of no return when no treatment is effective.

\section{Future prospects}

During recent past, a series of important advancements in the areas of molecular pathogenesis and experimental therapy have taken place, reflected in a molecular paradigm shift in the techniques and approaches applied to the study of IgAN (Novak et al., 2001). Ongoing and future investigations in this area will lead to the development of new noninvasive molecular tests for the diagnosis and prognosis, and the application of these discoveries to the rational design of tailored therapeutic agents.

\section{References}

Ballardie FW, O'Donoghue DJ, \& Feehally J. (1987). Increasing frequency of adult IgA nephropathy in the UK? Lancet, Vol. 330, No. 8568, pp.1205.

Barratt J, Feehally J, \& Smith AC. (2004). Pathogenesis of IgA nephropathy. Semin Nephrol, Vol. 24, No. 3, pp. 197-217.

Bartosik LP, Lajoie G, Sugar L, \& Cattran DC. (2001). Predicting progression in IgA nephropathy. Am J Kidney Dis, Vol. 38, No. 4, pp. 728-35.

Bellur SS, Troyanov S, Cook HT, \& Roberts ISD. (2011). Immunostaining findings in IgA nephropathy: correlation with histology and clinical outcome in the Oxford classification patient cohort. Nephrol Dial Transplant, Vol. 26, No. 8, pp. 2533-36.

Berger J, \& Hinglais N. (1968). Les dépôts intercapillaires d'IgA-IgG. J Urol Nephrol, Vol. 74, pp. 694-5.

Floege J, \& Feehally J. (2000). IgA nephropathy: recent developments. J Am Soc Nephrol, Vol. 11, No. 12, pp. 2395-2403.

Coppo R, \& Amore A. (2004). Aberrant glycosylation in IgA nephropathy (IgAN). Kidney Int, Vol. 65, No. 5, pp. 1544-7.

Cattran DC, Coppo R, Cook T, Feehally J, Roberts ISD, Troyanov S, Alpers CE, Amore A, Barratt J, Berthoux F, Bonsib S, Bruijn JA, D'Agati V, D'Amico G, Emancipator S, Emma F, Ferrario F, Fervenza FC, Florquin S, Fogo A, Geddes CC, Groene HJ, Haas M, Herzenberg AM, Hill PA, Hogg RJ, Hsu SI, Jennette JC, Joh K, Julian BA, Kawamura T, Lai FM, Leung CB, Li LS, Li PK, Liu ZH, Mackinnon B, Mezzano S, Schena FP, Tomino Y, Walker PD, Wang H, Weening JJ, Yoshikawa N, \& Zhang H. (2009). The Oxford classification of IgA nephropathy: rationale, clinicopathologic correlations, and classification. Kidney Int, Vol. 76, No. 5, pp. 534-45.

Chandrika BK. (2009). IgA nephropathy in Kerala, India: a retrospective study. Indian J Pathol Microbiol, Vol. 52, No. 1, pp.14-16.

D'Amico G. (2004). Natural history of idiopathic IgA nephropathy and factors predictive of disease outcome. Semin Nephrol Vol. 24, No. 3, pp. 179-96.

D'Amico G. (1985). The commonest glomerulonephritis in the world: IgA nephropathy. Q J Med, Vol. 64, No. 245, pp. 709-27. 
Donadio JV, \& Grande JP. IgA nephropathy. (2002). New Engl J Med, 347, No. 10, p. 738-48.

Galla JH. (1995). IgA nephropathy. Kidney Int, Vol. 47, No. 2, pp. 377-87.

Geddes CC, Rauta V, Gronhagen-Riska C, Bartosik LP, Jardine AG, Ibels LS, Pei Y, \& Cattran DC. (2003). A tricontinental view of IgA nephropathy. Nephrol Dial Transplant, Vol. 18, No. 8, pp. 1541-8.

Hass M. (1997). Histologic sub-classification of IgA nephropathy: a clinicopathologic study of 244 cases. Am J Kidney Dis, Vol. 29, No. 6, pp. 829-42.

Herzenberg AM, Fogo AB, Reich HN, Troyanov S, Bavbek N, Massat AE, Hunley TE, Hladunewich MA, Julian BA, Fervenza FC, Cattran DC. (2011). Validation of the Oxford classification of IgA nephropathy. Kidney Int, Vol. 80, pp. 310-7.

Hsu SI, Ramirez SB, Winn MP, Bonventre JV, \& Owen WF. (2000). Evidence for genetic factors in the development and progression of IgA nephropathy. Kidney Int, Vol. 57, No. 5, pp. 1818-35.

Julian BA, Waldo FB, Rifai A, \& Mestecki J. (1988). IgA nephropathy, the most common glomerulonephritis worldwide. A neglected disease in the United States? Am J Med, Vol. 84, No. 1, pp. 129-32.

Kazi JI, Mubarak M, Ahmed E, Akhter F, Naqvi SAA, \& Rizvi SAH. (2009). Spectrum of glomerulonephritides in adults with nephrotic syndrome in Pakistan. ClinExp Nephrol, Vol. 13, No. 1, pp. 38-43.

Koyama A, Igarashi M, \& Kobayashi M. Members and coworkers of the Research group on progressive renal diseases. (1997). Natural history and risk factors for Immunoglobulin A nephropathy in Japan. Am J Kidney Dis, Vol. 29, No. 4, pp. 52632.

Lai FMM, To KF, Choi PCL, \& Li PKT. (1999). Primary immunoglobulin A nephropathy through the retrospectroscope. Hong Kong Med J, Vol. 5, No. 4, pp. 375-82.

Lee HS, Lee MS, Lee SM, Lee SY, Lee ES, Lee EY, et al. (2005). Histological grading of IgA nephropathy predicting renal outcome: Revisiting H.S. Lee's glomerular grading system. Nephrol Dial Transplant, Vol. 20, No. 2, pp. 342-8.

Manno C, Strippoli G, D'Altri C, Torres D, Rossini M, \& Schena F. (2007). A novel simpler histological classification for renal survival in IgA Nephropathy: A retrospective study. Am J Kidney Dis,, Vol. 49, No. 6, pp. 763-75.

Mubarak M. (2009). The prevalence of IgA nephropathy in Pakistan: only a tip of the iceberg. J Pak Med Assoc, Vol. 59, No. 10, pp. 733.

Mubarak M, Lanewala A, Kazi JI, Akhter F, Sher A, Fayyaz A, \& Bhatti S. (2009). Histopathological spectrum of childhood nephrotic syndrome in Pakistan. Clin Exp Nephrol, Vol. 13, No. 6, pp. 589-93.

Mubarak M. (2009). Nomenclature of the Oxford classification of IgA nephropathy: do we need to be careful? Kidney Int, Vol. 77, No. 1, pp. 74.

Narasimhan B, Chacko B, John GT, Korula A, Kirubakaran MG, \& Jacob CK. (2006). Characterization of kidney lesions in Indian adults: towards a renal biopsy registry. J Nephrol, Vol. 19, No. 2, pp. 205-10.

Novak J, Julian BA, Tomana M, \& Mestecky J. (2001). Progress in molecular and genetic studies of IgA nephropathy. J Clin Immunol, Vol. 21, No. 5, pp. 310-27.

Power DA, Murhead N, \& Simpson JG. (1985). IgA nephropathy is not a rare disease in the United Kingdom. Nephron Vo. 40, No. 2, pp. 180-4. 
Rivera F, Lopez-Gomez JM, \& Perez Garcia R. (2004). Clinicopathologic correlations of renal pathology in Spain. Kidney Int, Vol. 66, No. 3, pp. 898-904.

Roberts ISD, Cook T, Troyanov S, Alpers CE, Amore A, Barratt J, Berthoux F, Bonsib S, Bruijn JA, Cattran DC, Coppo R, D'Agati V, D'Amico G, Emancipator S, Emma F, Feehally J, Ferrario F, Fervenza FC, Florquin S, Fogo A, Geddes CC, Groene HJ, Haas M, Herzenberg AM, Hill PA, Hogg RJ, Hsu SI, Jennette JC, Joh K, Julian BA, Kawamura T, Lai FM, Li LS, Li PK, Liu ZH, Mackinnon B, Mezzano S, Schena FP, Tomino Y, Walker PD, Wang H, Weening JJ, Yoshikawa N, \& Zhang H. (2009). The Oxford classification of IgA nephropathy: pathology definitions, correlations and reproducibility. Kidney Int, Vol. 76, No. 5, pp. 546-56.

Schena FP and the Italian Group of Renal Immunopathology. Survey of the Italian Registry of renal biopsies. (1997). Frequency of the renal diseases for 7 consecutive years. Nephrol Dial Transplant, Vol. 12, No. pp. 3, pp. 418-26.

Seedat YK, Nathoo BC, Parag KB, Naiker IP, \& Ramsaroop R. (1988). IgA nephropathy in Blacks and Indians of Natal. Nephron, Vol. 50, No. 2, pp. 37-41.

Sinniah R. (1980). Renal disease in Singapore with particular reference to glomerulonephritis in adults. Singapore Med J, Vol. 21, No. 3, pp. 583-91.

Stratta P, Segoloni GP, Canavese C, Sandri L, Mazzucco G, Roccatello D, Manganaro M, \& Versellone A. (1996). Incidence of biopsy-proven primary glomerulonephritis in an Italian province. Am J Kidney Dis, Vol. 27, No. 5, pp. 631-9.

Yahya TM, Pingle A, Boobes Y, \& Pingle S. (1997). Analysis of 490 kidney biopsies: data from the United Arab Emirates renal diseases registry. J Nephrol, Vol. 11, No. 3, pp. 148-50. 


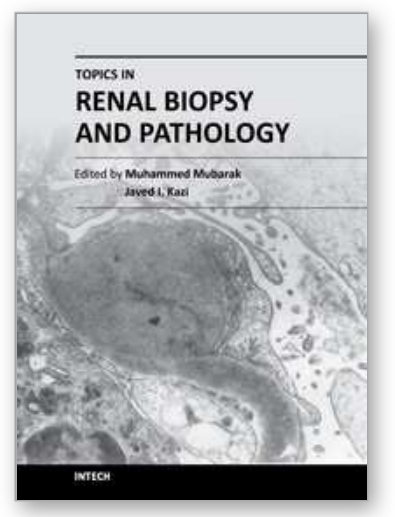

\author{
Topics in Renal Biopsy and Pathology \\ Edited by Dr. Muhammed Mubarak
}

ISBN 978-953-51-0477-3

Hard cover, 284 pages

Publisher InTech

Published online 04, April, 2012

Published in print edition April, 2012

There is no dearth of high-quality books on renal biopsy and pathology in the market. These are either single author or multi-author books, written by world authorities in their respective areas, mostly from the developed world. The vast scholarly potential of authors in the developing countries remains underutilized. Most of the books share the classical monotony of the topics or subjects covered in the book. The current book is a unique adventure in that it bears a truly international outlook and incorporates a variety of topics, which make the book a very interesting project. The authors of the present book hail not only from the developed world, but also many developing countries. The authors belong not only to US but also to Europe as well as to Pakistan and Japan. The scientific content of the book is equally varied, spanning the spectrum of technical issues of biopsy procurement, to pathological examination, to individual disease entities, renal graft pathology, pathophysiology of renal disorders, to practice guidelines.

\title{
How to reference
}

In order to correctly reference this scholarly work, feel free to copy and paste the following:

Muhammed Mubarak and Javed I. Kazi (2012). Recent Developments in the Pathogenesis and the Pathological Classification of IgA Nephropathy, Topics in Renal Biopsy and Pathology, Dr. Muhammed Mubarak (Ed.), ISBN: 978-953-51-0477-3, InTech, Available from: http://www.intechopen.com/books/topics-inrenal-biopsy-and-pathology/recent-developments-in-the-pathogenesis-and-the-pathological-classification-ofiga-nephropathy

\section{INTECH}

open science | open minds

\section{InTech Europe}

University Campus STeP Ri

Slavka Krautzeka 83/A

51000 Rijeka, Croatia

Phone: +385 (51) 770447

Fax: +385 (51) 686166

www.intechopen.com

\section{InTech China}

Unit 405, Office Block, Hotel Equatorial Shanghai

No.65, Yan An Road (West), Shanghai, 200040, China

中国上海市延安西路65号上海国际贵都大饭店办公楼 405 单元

Phone: +86-21-62489820

Fax: +86-21-62489821 
(C) 2012 The Author(s). Licensee IntechOpen. This is an open access article distributed under the terms of the Creative Commons Attribution 3.0 License, which permits unrestricted use, distribution, and reproduction in any medium, provided the original work is properly cited. 